\title{
Kinetic Modelling of Vitamin C Degradation in Selected Fruits under Market Storage Conditions
}

\author{
* Nkwocha, A.C.; Ekeke, I.C.; Kamalu, C.I.O.; Oghome, P.I.; Osoka, E.C.; and \\ Nkuzinna, O.C.
}

\author{
Department of Chemical Engineering, Federal University of Technology, P.M.B 1526, Owerri , Nigeria \\ *Corresponding Author \\ Email: chinkwocha2014@gmail.com
}

\begin{abstract}
The degradation kinetics of vitamin $C$ in three fruits namely; orange, banana and apple under different market storage conditions prevalent in Nigeria were investigated. Orange and banana samples were stored in sacks and open air at ambient conditions, while open air and refrigerator were used for apple samples. Storage was for 6 days duration. .Iodometric titration was used to determine vitamin $C$ content of the fruits on a daily basis. Regression analysis was employed to fit the variations in vitamin $C$ concentration in the different samples with time, to three kinetic models, to determine which model best describes the degradation trend. Results showed that vitamin $C$ concentration in all the fruit samples reduced over time following zero order kinetics. Kinetic studies obtained the following degradation rate constants: orange $0.44 g . L^{-1} \cdot s^{-1}$ and $0.29 g . L^{-1} \cdot s^{-1}$, for sack and open air storage respectively, banana $0.316 \mathrm{~g} \cdot \mathrm{L}^{-1} \cdot \mathrm{s}^{-1}$ and $0.264 \mathrm{~g} \cdot \mathrm{L}^{-1} \cdot \mathrm{s}^{-1,}$ for sack and open air, and apple $0.122 \mathrm{~g} . \mathrm{L}^{-1} \cdot \mathrm{s}^{-1}$ and $0.188 \mathrm{~g} . \mathrm{L}^{-}$ ${ }^{1} . s^{-1}$, for refrigerated and open air respectively. The study indicated that with respect to vitamin $C$ retention, open air storage is preferable to sack for oranges and bananas while apples are preferably stored in refrigerator.
\end{abstract}

Keywords- Diet, samples, rate constant, open air, biological activity, anti-oxidant.

\section{INTRODUCTION}

Fruits such as orange, banana, mango and apple are a major component of a healthy diet. They are low in fat and provide significant levels of some micronutrients. Most fruits when ripe have a short durability, which is further reduced when the fruits are exposed to unfavourable conditions during transportation, processing and storage. Fruits are important sources of vitamin C. (Giannakouurou et al., 2003).

Vitamin $\mathrm{C}$ is defined as the generic term for all compounds exhibiting the biological activity of L-ascorbic acid (AA) (Lee et al., 2000). Vitamin C or ascorbic acid is a nutrient that is valuable for its antioxidant effect (Giannakouurou $e t$ $a l ., 2003)$. It is a water soluble vitamin, and very essential to www.ijeab.com human beings (Uddin et al., 2002). Most plants and animals have the ability to synthesize vitamin C. The only mammals that are unable to synthesize vitamin $\mathrm{C}$ are primates, including man, and guinea pigs. Therefore, humans depend on exogenous sources of the vitamin which include fruits and vegetables as well as food supplements and pharmaceutical preparations (Parviainen, 1995). Vitamin C is required for the synthesis of collagen, an important structural component of blood vessels, tendons, ligaments and bone. It is also important in the synthesis of the neurotransmitter norepinephrine, which is critical to brain function and can affect mood.

Vitamin C content of fruits vary depending on fruit size and species. Oranges contain about $50 \mathrm{mg} / 100 \mathrm{~g}$, while banana and apple contain $9 \mathrm{mg} / 100 \mathrm{~g}$ and $6 \mathrm{mg} / 100 \mathrm{~g}$ respectively (Bellow and Krebs, 2007). Vitamin C is easily destroyed and various studies have been carried out on the rate of vitamin $\mathrm{C}$ degradation in foods and fruits alike, and various kinetic models adopted. However, the vitamin $\mathrm{C}$ degradation mechanism is specific to a particular system, as it depends on several factors (Tannenbaum, 1976), such as temperature, water activity, $\mathrm{pH}$ and metal ions (Masamba et al., 2013). Vitamin $C$ is most sensitive to destruction when the commodity is subjected to adverse handling and storage conditions. Losses are enhanced by extended storage, higher temperatures, low relative humidity, physical damage, and chilling injury (Lee and Kaddar, 2000). Ascorbic acid is recognized as one of the most heat sensitive nutrients in foods, therefore, it is a marker of the loss of other nutrients (Esteve et al., 1999 ). Numerous analytical techniques are available for the determination of the vitamin $\mathrm{C}$ content in various fruits and vegetables, amongst them are iodometric titration, chromatographic methods, enzymatic methods, and electrochemical methods (Abraha et al., 2014; Gunjun and Mangla, 2012; Iwase, 2000).

This study was carried out to (i) determine the rate of degradation of vitamin $\mathrm{C}$ in orange, banana and apple under the market storage methods prevalent in Nigeria namely; 
ambient storage in open air, sack storage, and refrigeration, so as to recommend the best option; (ii) develop kinetic models for predicting vitamin $\mathrm{C}$ degradation in the selected fruits under the studied conditions.

\section{MATERIALS AND METHOD}

Source and preparation of samples

Ripe and fresh fruits were purchased from Relief market in Owerri, Nigeria. The fruit samples were divided into two groups and stored using the different market storage methods. The first group of oranges, apples and bananas were kept on a tray and exposed to open air under ambient conditions, the second group of oranges and bananas were packed in two separate jute bags and kept on concrete floor, while the apples were stored in a refrigerator. The fruits were stored for a period of 6 days. The fruit juice from the orange and banana samples was prepared by blending $100 \mathrm{~g}$ of the fruit sample with $50 \mathrm{ml}$ of distilled water and the mixture strained. Distilled water was then added to make a final solution of $100 \mathrm{ml}$ in a volumetric flask. The apple samples were squeezed to extract the juice.

Preparation of standard solution

Starch solution was prepared by dissolving $0.5 \mathrm{~g}$ soluble starch in $50 \mathrm{ml}$ near boiling distilled water, while vitamin $\mathrm{C}$ solution was prepared by dissolving $0.25 \mathrm{~g}$ of standard vitamin $\mathrm{C}$ in $100 \mathrm{ml}$ of distilled water, and the solution was diluted to $250 \mathrm{ml}$ with distilled water. $5 \mathrm{~g}$ of potassium iodide (KI) and $0.268 \mathrm{~g}$ of potassium iodate $\left(\mathrm{KIO}_{3}\right)$ were dis solved in $200 \mathrm{ml}$ of distilled water, and $300 \mathrm{ml}$ of $3 \mathrm{M}$ sulphuric acid $\left(\mathrm{H}_{2} \mathrm{SO}_{4}\right)$ was added to obtain standard iodine solution.

\section{Sample analysis}

The iodine solution was titrated with $25 \mathrm{ml}$ of the standard vitamin $\mathrm{C}$ solution, and then with $25 \mathrm{ml}$ of prepared fruit juice samples using starch indicator. Triplicate samples were analyzed and the average titre used for calculation.

a) Calculation of the mass of vitamin $C$ present in fruit sample - The mass of vitamin C contained in each of the samples was calculated from the relationship:

volume of iodine solutionrequined to react with standard vitamin $C$ sample mass of standand vitamin $C$ used

volume of iodine solutionrequined to react with vitamin $C$ in fruit sample mass of vitamin $C$ in fruit sample

(1) b) Calculation of the Concentration of vitamin $C$ present in fruit sample - This was carried out using the relationship:

Concentration of vitamin $\mathrm{C}=$ mass of vitamin $C$ in fruit sample volume of fruit juice sampleused

\section{Kinetic modelling}

The degradation of vitamin $\mathrm{C}$ was modeled using the integral rate law. Different models were fitted using the integral method of analysis. The integral law equation is stated as;

$$
\frac{d C}{d t}=-k[C]^{n}
$$

where $k=$ rate constant

$$
\begin{aligned}
& C=\text { concentration of vitamin } \mathrm{C} \text { in sample at time } \mathrm{t} \\
& \mathrm{n}=\text { order of reaction }
\end{aligned}
$$

This equation was used to develop three models based on concentration (for order of reactions $n=0,1$ and 2) and their as sociated half lives $\left(\mathrm{t}_{1 / 2}\right)$.

Zero order model $(\mathrm{n}=0)$ is given as:

$C=C_{0}-k t$

$t_{1 / 2}=C_{0 / 2 k}$

First order model $(\mathrm{n}=1)$

$$
\begin{aligned}
& \ln (C)=\ln \left(C_{0}\right)-k t \\
& t_{1 / 2}=\ln (2) /_{k}
\end{aligned}
$$

Second order model $(n=2)$ :

$$
\begin{aligned}
& \frac{1}{\mathrm{C}}=\frac{1}{c_{0}}+k t \\
& t_{1 / 2}=1 / k C_{0}
\end{aligned}
$$

where $C_{0}=$ initial concentration of vitamin $C$ in sample

$$
t_{1 / 2}=\text { half-life of vitamin } \mathrm{C} \text { in sample }
$$

Concentration or a function of concentration was plotted against time for each model and regression analysis was used to determine the 'Goodness of fit' employing Matlab software (Version 8.2, MathWorks Inc., USA). Goodness of fit is characterized by Coefficient of Determination $\left(\mathrm{R}^{2}\right)$, 
Sum of Squared Errors (SSE), and Root Mean Sum of Errors (RMSE). The model with maximum $\mathrm{R}^{2}$ and minimum RMSE is adjudged the best (Silva et al., 2011; Mitra et al., 2011)

\section{RESULTS AND DISCUSSION}

The variations in vitamin $\mathrm{C}$ concentration of fruit samples during storage are presented in Tables 1 - 3. Tables 4- 6 summarize the results of kinetic model regression analysis, while Table 7 compares vitamin $\mathrm{C}$ zero order degradation kinetic parameters for the samples under different storage methods. As can be observed in Tables 1-3, the concentration of vitamin $\mathrm{C}$ decreased steadily with time during storage in all the samples. This confirms the fact that vitamin $\mathrm{C}$ degrades during storage in fruits. The vitamin $\mathrm{C}$ concentration of the fruit samples decreased during storage, but in different degrees, depending on the method of storage. This is in agreement with the report of earlier workers on citrus and strawberry fruit juices (Burdurlu et al., 2006; Derossi et al., 2010,) and in accordance with the degradation kinetics of ascorbic acid in model systems as put forth by Liao and Seib (1988). Besides, it is also evident that the ascorbic acid content in a given mass of orange is greater than that in an equal mass of banana and apple.

A visual inspection of the kinetic plots of models (4a), (5a) and (6a) respectively, presented in Figures 1-3 for orange, Figures 4-6 for banana, and Figures 7-9 for apple, shows that the zero order, that is, model (4a) fitted the kinetic data best in all fruit samples. This is confirmed by the goodness of fit data in Tables 3, 4, and 5. The zero order kinetics exhibited $\mathrm{R}^{2}$ values; 0.9335, 0.9822 and RMSE values; $0.1621,0.1229$ for orange under open air and sack storage respectively, $\mathrm{R}^{2}$ values; 0.9312, 0.9558 and RMSE values; $0.1505,0.1424$ for open air and sack storage respectively for banana, and $\mathrm{R}^{2}$ values; 0.9850, 0.9574 and RMSE values; $0.0486,0.05395$ for apple under open air and refrigerated storage respectively.

The zero order model generally exhibited the highest $\mathrm{R}^{2}$ values and the lowest RMSE values. Thus, the vitamin C degradation kinetics in orange, banana and apple can be best described by zero order kinetics. . Furthermore, the degradation rate constants of fruit samples stored in sacks were generally higher than those kept in open air and refrigeration. Refrigerated samples exhibited lower rate constants relative to open air for apple. Since the magnitude of the rate constant is a reflection of the rate of reaction, the inference is that degradation of vitamin $\mathrm{C}$ occurred faster in samples stored in sacks than in those exposed to the air, and slower in refrigerated samples for apple. This trend manifested in the half life of the samples. The time at which the concentration of vitamin $\mathrm{C}$ in the samples reduces to half of its original amount (half life) was shorter in sack stored samples for orange and banana, and longer in refrigerated samples for apple. This implies that the air exposed and refrigerated samples will be expected to have longer shelf life than the sacked ones. Refrigerated apple samples recorded the longest half life of 10.79 days, with a proposed zero order model $\mathrm{C}=\mathrm{C}_{0}-0.1223 \mathrm{t}$, while sacked banana exhibited the shortest half life of 2.40days with the proposed model $\mathrm{C}=\mathrm{C}_{0}-0.3166 \mathrm{t}$. These models and others presented in Table 7 are proposed for monitoring vitamin $\mathrm{C}$ degradation for the respective fruits under the indicated market storage conditions.

Table.1: Vitamin C concentration in orange during storage

\begin{tabular}{ccc}
\hline Time (day) & \multicolumn{2}{c}{ Concentration $(\mathrm{g} / \mathbf{l})$} \\
\cline { 2 - 3 } 1 & Open air & Sack \\
& 3.76 & 4.24 \\
\hline 2 & 3.68 & 3.96 \\
3 & 3.52 & 3.64 \\
4 & 3.20 & 3.20 \\
5 & 2.80 & 2.64 \\
6 & 2.32 & 2.04 \\
\hline
\end{tabular}

Table.2: Vitamin C concentration in banana during storage

\begin{tabular}{ccc}
\hline Time (day) & \multicolumn{2}{c}{ Concentration $(\mathbf{g} / \mathbf{l})$} \\
\cline { 2 - 3 } 1 & Open air & Sack \\
1.32 & 1.52 \\
\hline 2 & 1.16 & 1.32 \\
3 & 0.92 & 0.88 \\
4 & 0.30 & 0.36 \\
5 & 0.28 & 0.20 \\
6 & 0.12 & 0.10 \\
\hline
\end{tabular}

Table.3: Vitamin C concentration in apple during storage

\begin{tabular}{lcc}
\hline Time (day) & \multicolumn{2}{c}{ Concentration $(\mathbf{g} / \mathbf{l})$} \\
\cline { 2 - 3 } 1 & Open air & Refrigerated \\
& 1.78 & 2.01 \\
\hline 2 & 1.44 & 1.63 \\
3 & 1.17 & 1.33 \\
4 & 0.98 & 1.10 \\
5 & 0.83 & 0.98 \\
6 & 0.68 & 0.72 \\
\hline
\end{tabular}


Table.4: Results of kinetic model regression analysis for orange

\begin{tabular}{lccccc}
$\begin{array}{l}\text { Storage } \\
\text { Method }\end{array}$ & $\begin{array}{c}\text { Kinetic order } \\
(\mathrm{n})\end{array}$ & $\mathbf{R}^{\mathbf{2}}$ & $\begin{array}{c}\text { Adjusted } \\
\mathrm{R}^{2}\end{array}$ & SSE & RMSE \\
\hline Open air & 0 & 0.9335 & 0.9169 & 0.00256 & 0.16210 \\
Sack & 0 & 0.9822 & 0.9778 & 0.06046 & 0.12290 \\
Open air & 1 & 0.9034 & 0.8792 & 0.01692 & 0.06505 \\
Sack & 1 & 0.9390 & 0.9238 & 0.02322 & 0.07619 \\
Open air & 2 & 0.8626 & 0.8282 & 0.02826 & 0.02658 \\
Sack & 2 & 0.8841 & 0.8551 & 0.00533 & 0.03652
\end{tabular}

Table.5: Results of kinetic model regression analysisfor banana

\begin{tabular}{lccccc}
\hline $\begin{array}{l}\text { Storage } \\
\text { Method }\end{array}$ & $\begin{array}{c}\text { Kinetic order } \\
(\mathrm{n})\end{array}$ & $\mathbf{R}^{\mathbf{2}}$ & $\begin{array}{c}\text { Adjusted } \\
\mathrm{R}^{2}\end{array}$ & SSE & RMSE \\
\hline Open air & 0 & 0.9312 & 0.9139 & 0.09057 & 0.15050 \\
Sack & 0 & 0.9558 & 0.9447 & 0.08113 & 0.14240 \\
Open air & 1 & 0.9264 & 0.9080 & 0.34240 & 0.29260 \\
Sack & 1 & 0.9548 & 0.9435 & 0.30590 & 0.27650 \\
Open air & 2 & 0.7893 & 0.7367 & 8.67800 & 1.49000 \\
Sack & 2 & 0.7408 & 0.6760 & 27.0600 & 2.60100 \\
\hline
\end{tabular}

Table.6: Results of kinetic model regression analysisfor apple

\begin{tabular}{lccccc}
\hline $\begin{array}{l}\text { Storage } \\
\text { Method }\end{array}$ & $\begin{array}{c}\text { Kinetic order } \\
(\mathrm{n})\end{array}$ & $\mathbf{R}^{\mathbf{2}}$ & $\begin{array}{c}\text { Adjusted } \\
\mathrm{R}^{2}\end{array}$ & SSE & RMSE \\
\hline Open air & 0 & 0.9850 & 0.9813 & 0.00944 & 0.04860 \\
Sack & 0 & 0.9574 & 0.9468 & 0.01164 & 0.05395 \\
Open air & 1 & 0.9639 & 0.9549 & 0.04399 & 0.10480 \\
Sack & 1 & 0.9505 & 0.9381 & 0.00244 & 0.02479 \\
Open air & 2 & 0.7408 & 0.6760 & 27.0600 & 2.60100 \\
Sack & 2 & 0.90450 & 0.8806 & 0.28960 & 0.69120 \\
\hline
\end{tabular}

Table.7: Comparison of zero order kinetic parameters and proposed model

\begin{tabular}{lccc}
\hline $\begin{array}{l}\text { Fruit samples } \\
\text { (Storage method) }\end{array}$ & $\begin{array}{c}\text { Rate constant } \\
\mathbf{k ~ g}(\mathbf{l d a y})^{-\mathbf{1}}\end{array}$ & $\begin{array}{c}\text { Half life } \\
\mathbf{t}_{\mathbf{1} / \mathbf{2}}(\mathbf{d a y})\end{array}$ & $\begin{array}{c}\text { Proposed } \\
\text { model }\end{array}$ \\
\hline $\begin{array}{l}\text { Orange } \\
\text { Open air }\end{array}$ & 0.2903 & 6.47 & $\mathrm{C}=\mathrm{C}_{0}-0.2903 \mathrm{t}$ \\
Sack & 0.4371 & 4.85 & $\mathrm{C}=\mathrm{C}_{0}-0.4371 \mathrm{t}$ \\
Banana & & & $\mathrm{C}=\mathrm{C}_{0}-0.2646 \mathrm{t}$ \\
$\begin{array}{l}\text { Open air } \\
\text { Sack }\end{array}$ & 0.2646 & 2.49 & $\mathrm{C}=\mathrm{C}_{0}-0.3166 \mathrm{t}$ \\
$\begin{array}{l}\text { Apple } \\
\text { Open air }\end{array}$ & 0.3166 & 2.40 & $\mathrm{C}=\mathrm{C}_{0}-0.1886 \mathrm{t}$ \\
Refrigerated & 0.1886 & 3.28 & $\mathrm{C}=\mathrm{C}_{0}-0.1223 \mathrm{t}$ \\
\hline
\end{tabular}




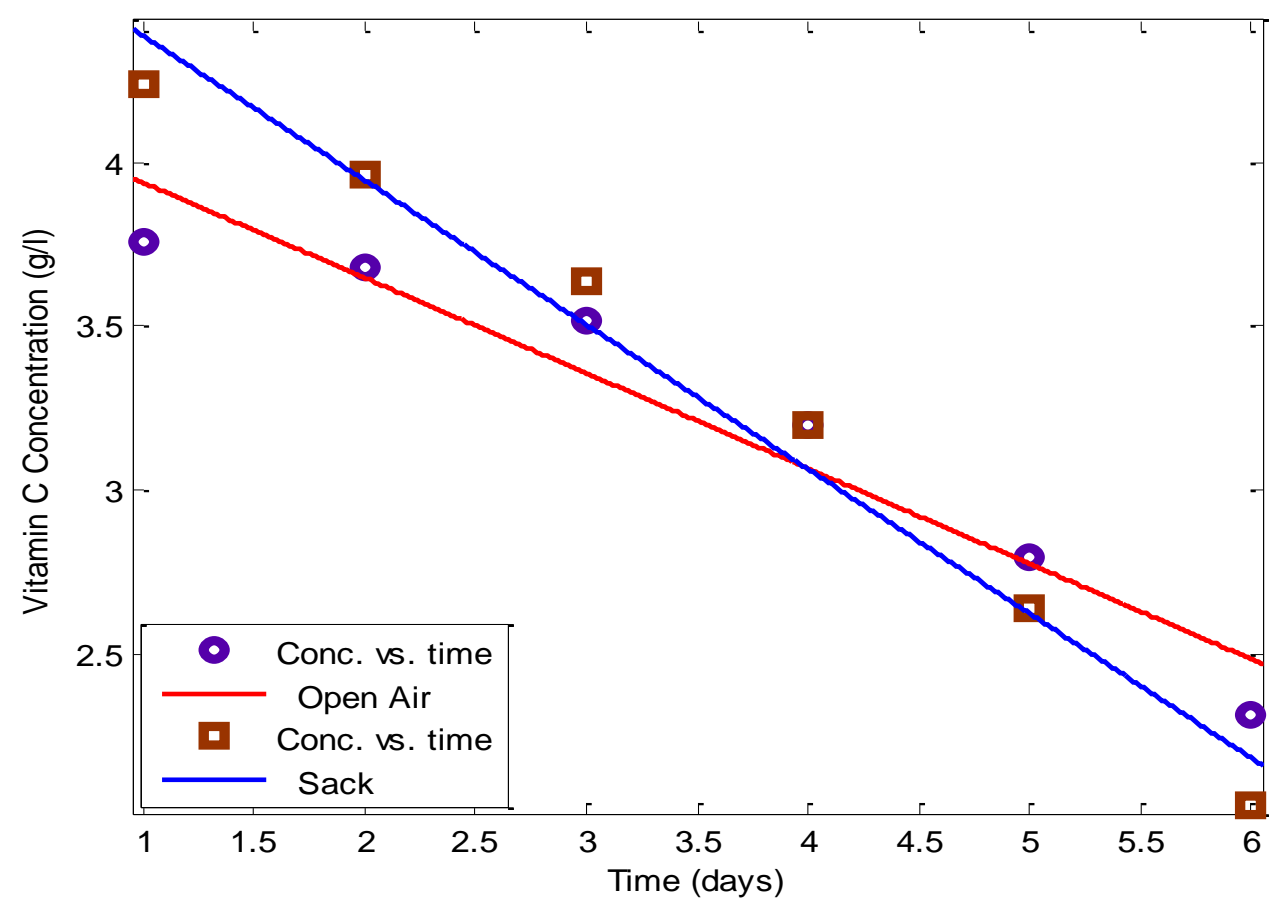

Fig.1: A plot of zero order kinetics for orange

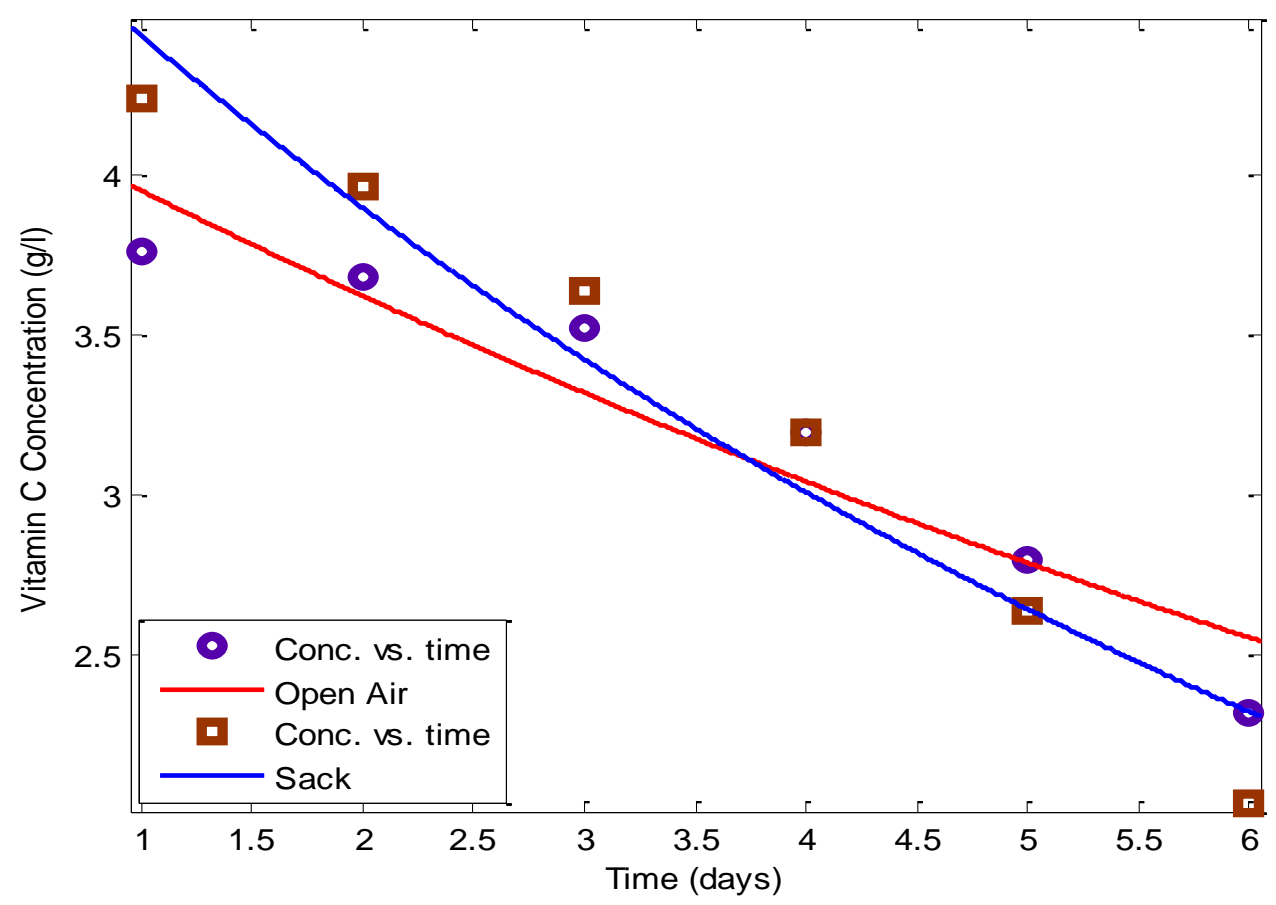

Fig.2: A plot offirst order kinetics for orange 


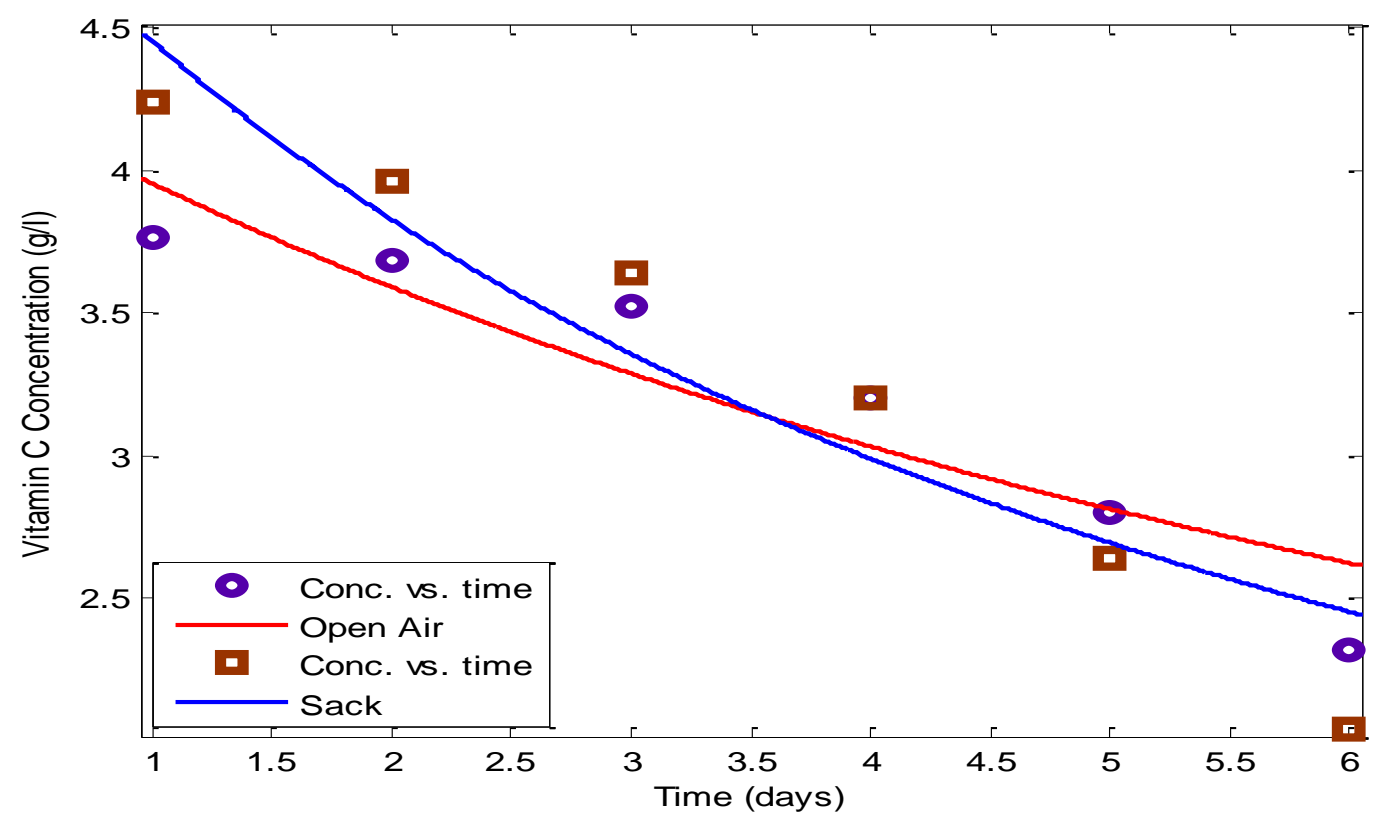

Fig.3: A plot of second order kinetics for orange

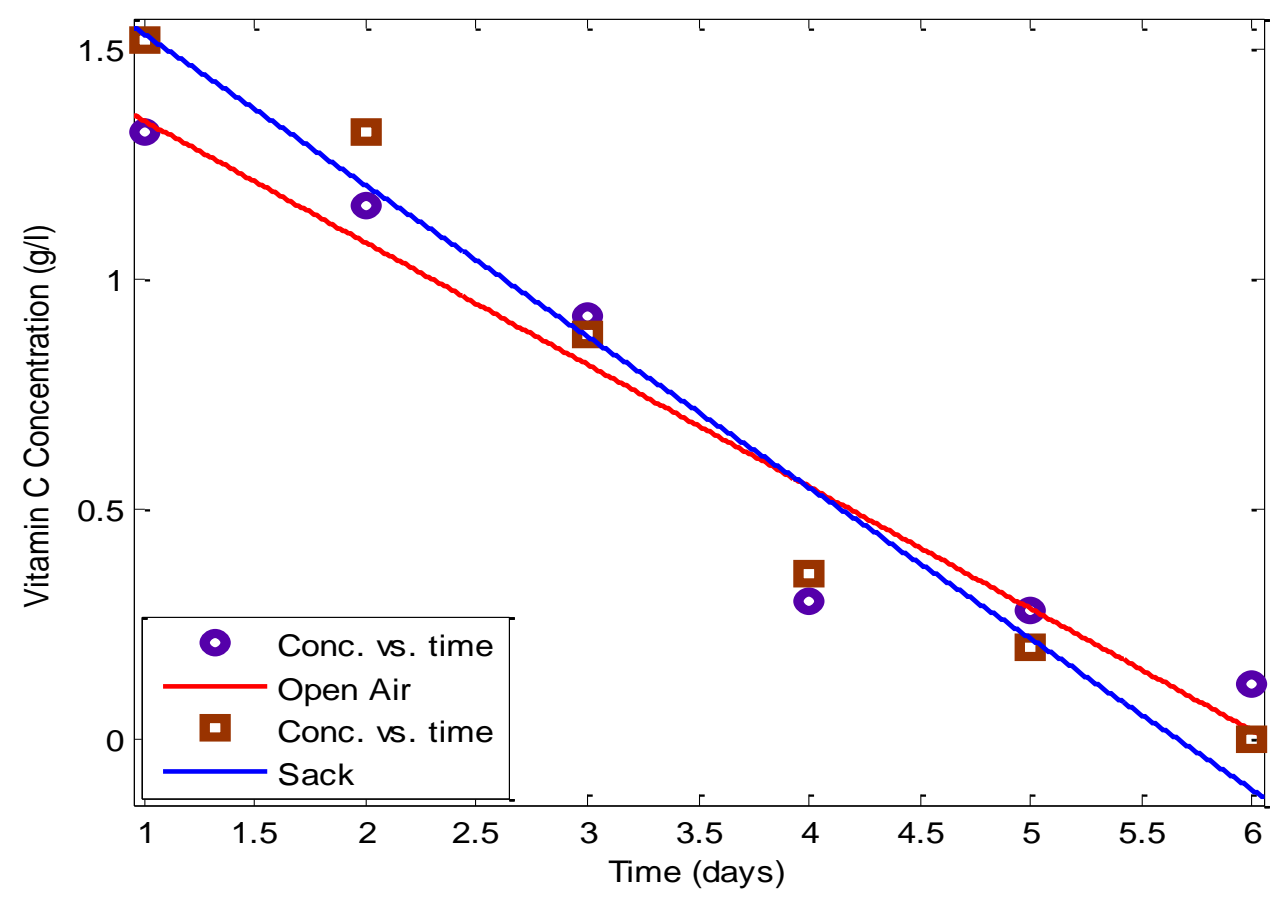

Fig.2: A plot of zero order kinetics for banana 


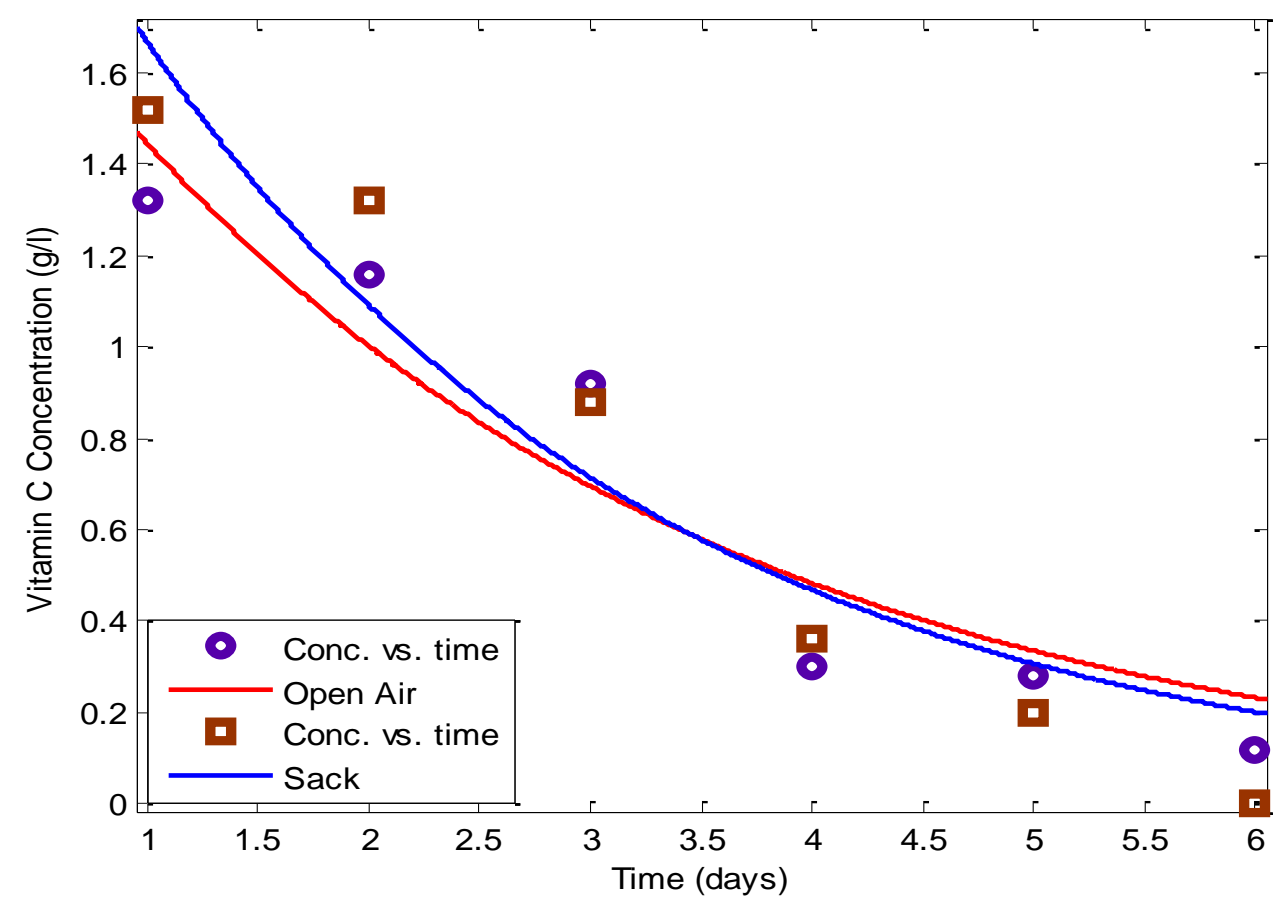

Fig.5: A plot offirst order kinetics for banana

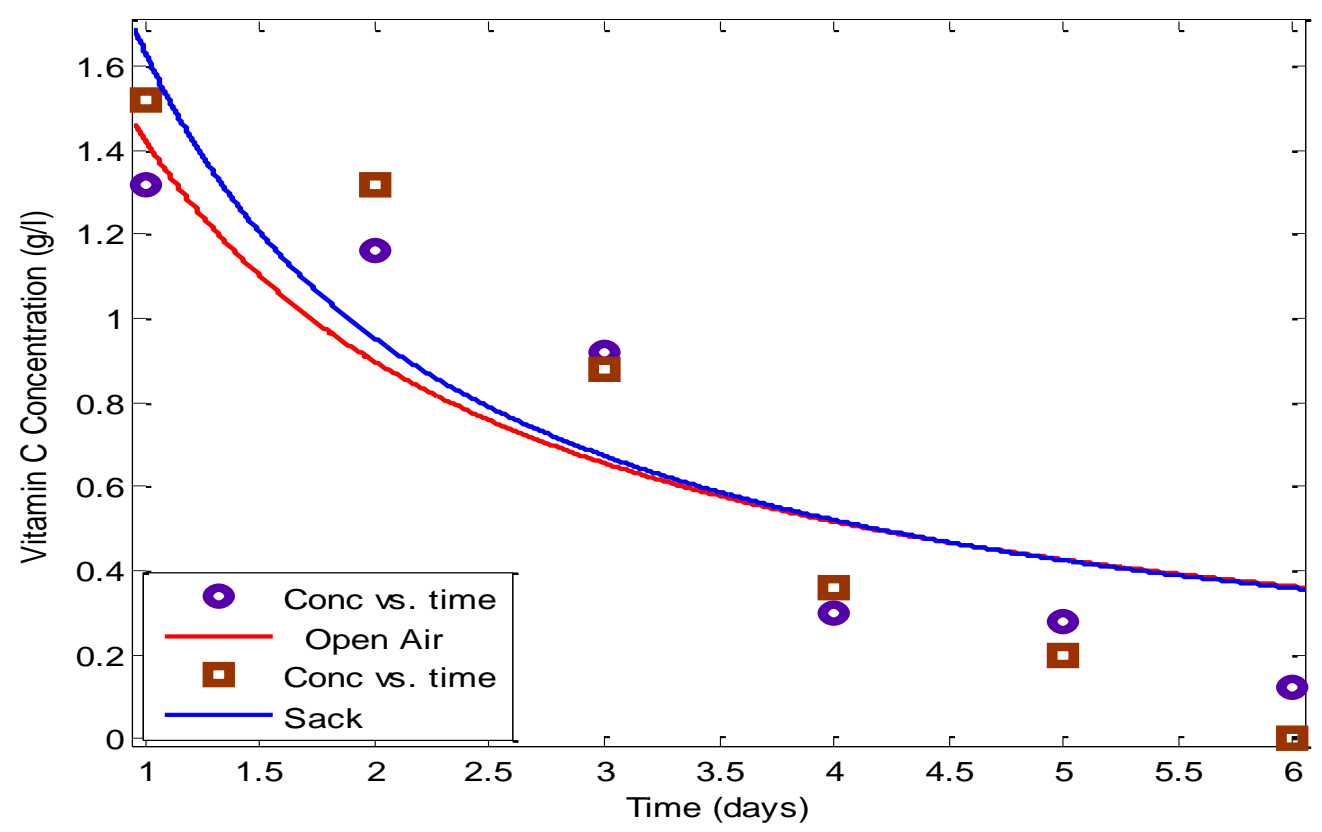

Fig.6: A plot of second order kinetics for banana 


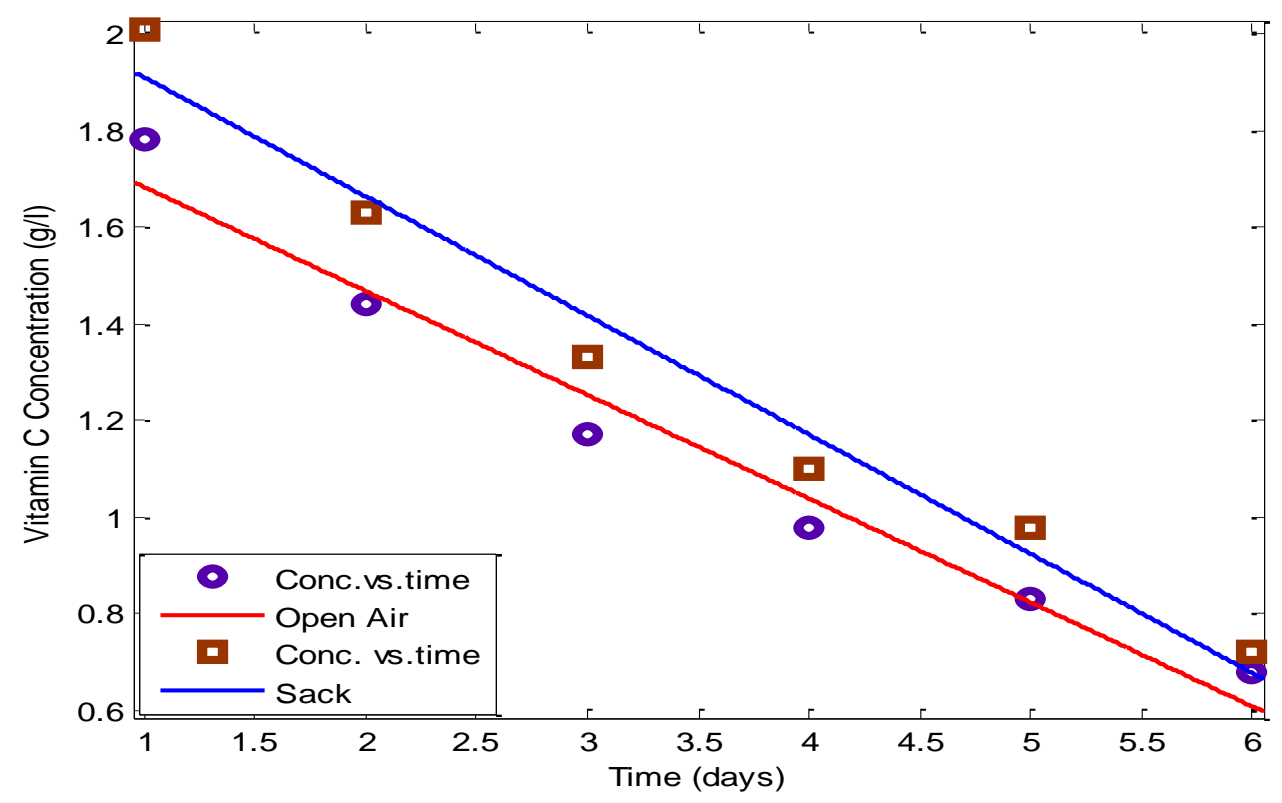

Fig.7: A plot of zero order kinetics for apple

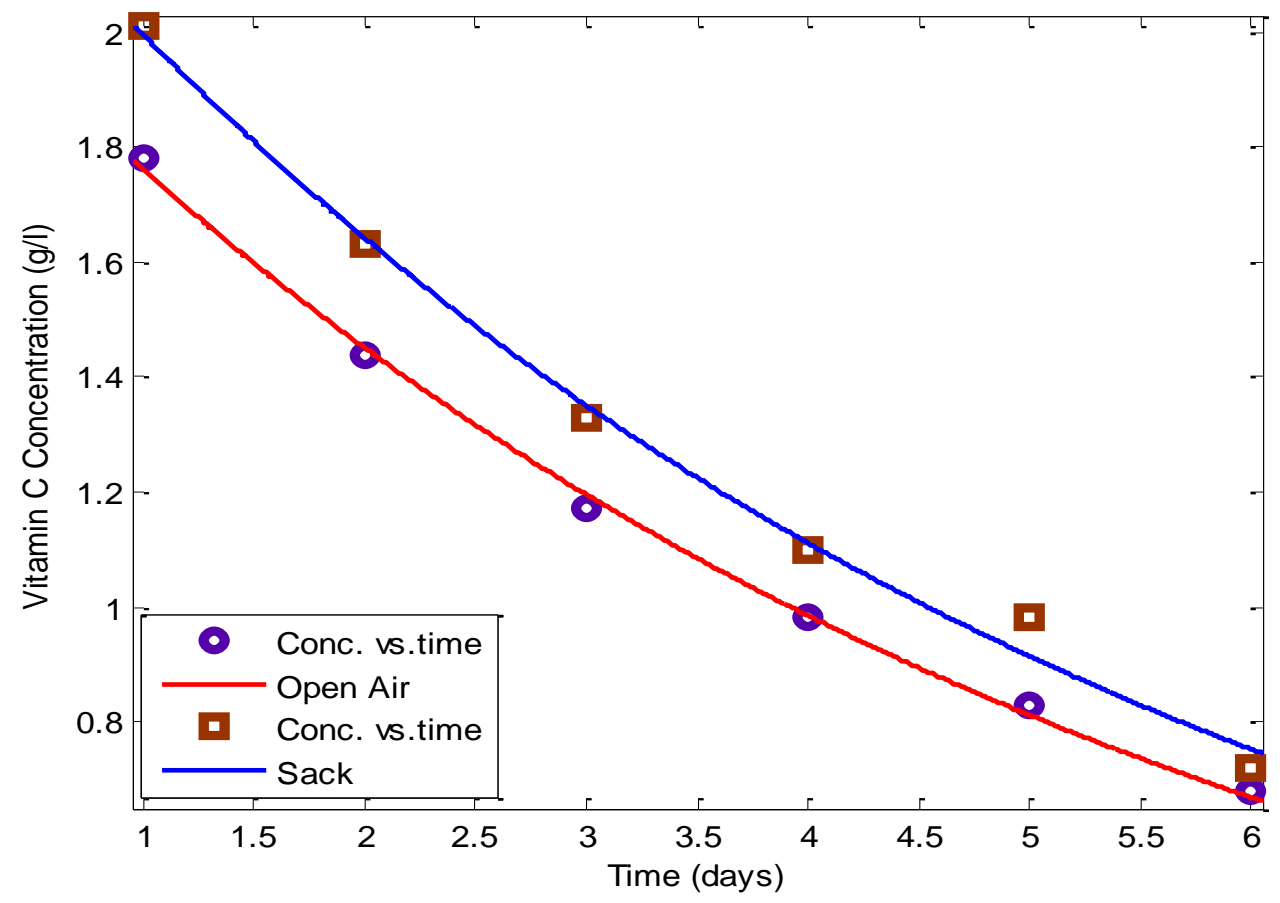

Fig.8: A plot of first order kinetics for apple 


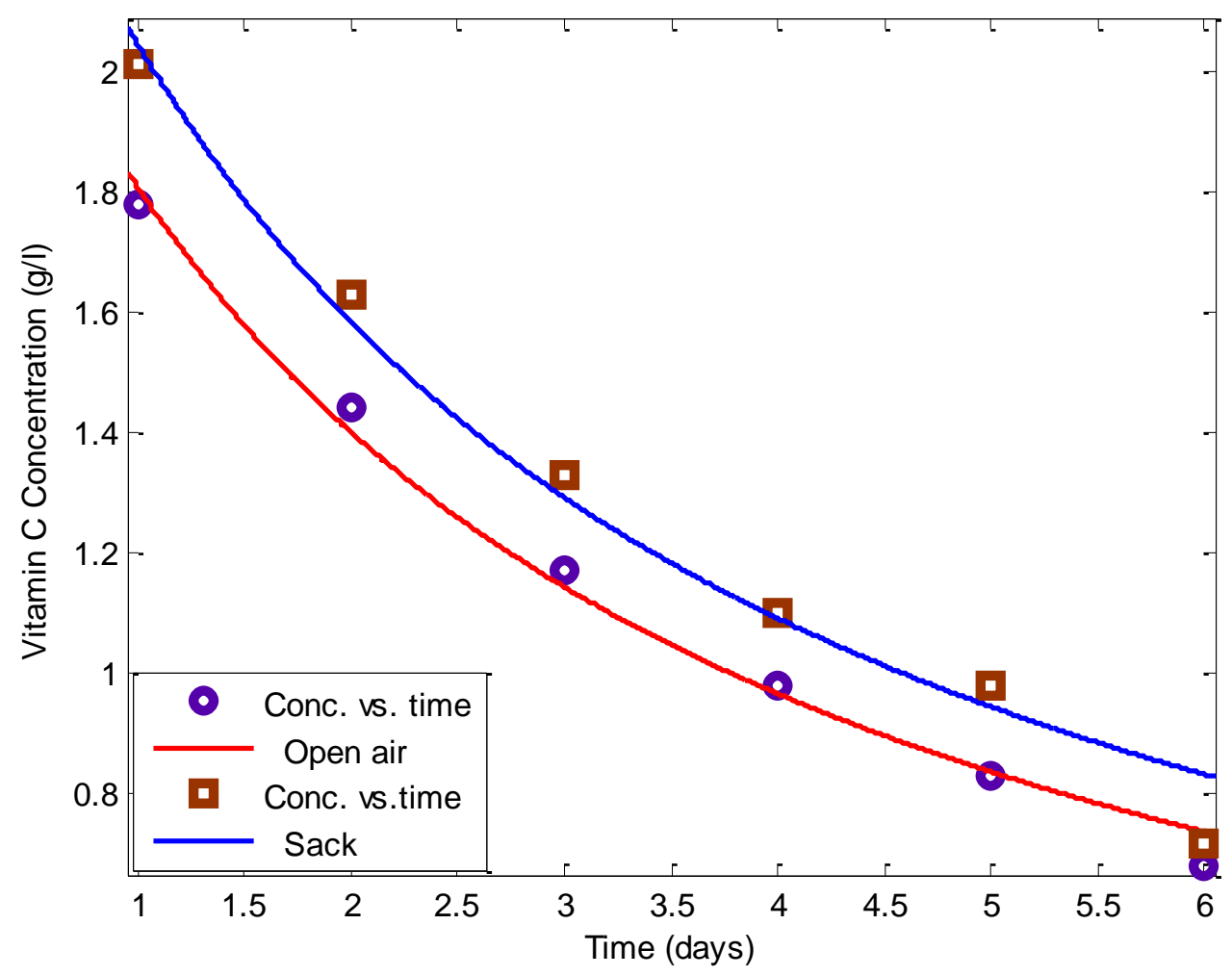

Fig.9: A plot of second order kinetics for apple

\section{CONCLUSION}

The influence of market storage conditions on vitamin $\mathrm{C}$ degradation in orange, banana and apple samples was evaluated in this study. Vitamin C content of these fruits decreased with time following zero order kinetics. It was found that open air storage and refrigeration helped to significantly reduce the rate of degradation when compared to storage in sacks as shown by the degradation rate constants and half lives. Thus, refrigeration for apples and open air storage for oranges and bananas are preferable in terms of vitamin $\mathrm{C}$ retention to sack storage, and hence, recommended for the storage of the indicated fruits in Nigeria local markets. However, in situations where refrigeration facilities are not available, properly managed open air storage can go a long way to retain vitamin $\mathrm{C}$ in apples for extended periods.

\section{REFERENCES}

[1] Abaha T., Subramania P.A.N., Amaha W., and Rishi P. (2014). Electrochemical determination and Comparison of ascorbic acid in freshly prepared and bottled fruit juices: A cyclic voltammetric study, $J$. Chem. Pharm. Res., 6(5), 880-888.
[2] Bellow, P.C. and Krebs, N.A. (2007). Vitamin C requirement of human adult. Experimental study of vitamin Deprivation in man, Lancet, pp. 853-858.

[3] Burdurlu, H.S., Koca, N., and Keradeniz, F. (2006). Degradation of vitamin $\mathrm{C}$ in citrus juice concentrate during storage, Journal of Food Engineering, Vol. 7 , Issue 2, $211-216$.

[4] Derossi, A., De Pulli, T., and Fione, A.G. (2010). Vitamin C kinetic degradation of strawberry juice stored under variable conditions. Journal of Food Science and Technology, 13, 590 - 595.

[5] Esteve, M. J., Frigola, A., Martorell, L., and Rodrigo, C. (1999). Kinetics of green asparagus ascorbic acid heated in a high-temperature thermo-resistometer. Zeitschrift für Lebensmittel Unterschung Forschung, A. 208, 144-147.

[6] Giannakouu rou, M.C., and Taoukis, P.S. (2003). Kinetic modelling of vitamin $\mathrm{C}$ loss in frozen green vegetables under variable storage conditions. Food Chemistry 83, 33-41.

[7] Gunjan, K., and Mangla, D.G. (2012). Analysis of vitamin $\mathrm{C}$ in commercial and natural substances found in Nimar and Malwa region by Iodometric Titration. $J$. Sci. Res. Phar., 1(2), 8. 
[8] Iwase H. (2000). Use of nucleic acids in the mobile phase for the determination of ascorbic acid in foods by high-performance liquid chromatography with electrochemical detection. J. Chromatogr. A. 881, 327-330.

[9] Lee, S.K. and Kader, A.A. (2000). Preharvest and postharvest factors influencing vitamin $\mathrm{C}$ content of Horticultural crops. Postharvest Biology and Technology, 20, 207-220.

[10] Liao M.L., and Seib, P.A. (1988). Chemistry of Lascorbic acid related to foods, Food Chemistry, 30, 289-312.

[11] Masamba, K.G., Mkandawire, M., Chiputula, J., and Nyirenda, K.S. (2013). Evaluation of sensory quality attributes and extent of vitamin $\mathrm{C}$ degradation in dried pineapple, mango and banana fruit pieces pre -treated with sodium metabisulphite and lemon juice. International Research Journal of Agricultural Science and Soil Science, 3(3), 75-80.

[12] Mitra, J., Shrivastava, S.L., and Rao, P.S. (2011). Vacuum dehydration kinetics of onion slices. Food and Bioproducts Processing, 89, 1 -9.

[13] Nichols, H. (2014). What are the health benefits of Tomatoes? Medical News Today. Medihexicon, intl.web.

[14] Silva, E.M., da Silva, J.S., Pena, R.S., and Rogez, H. (2011).. A combined approach to optimize the drying process of Flavonoid -rich leaves (Inga edulis) using experimental design and mathematical modeling. Food and Bioproducts Processing, 89, 39-46.

[15] Parviainen, M.T. (1995). In: A.Townsend (Ed.), Encyclopedia of Analytical Science. Vol. 9, Academic Press, London.

[16] Tannenbaum, S. (1976). Ascorbic acid. In: Principles of Food Science. Part I. Food chemistry,. $2^{\text {nd }}$ edition, Fennema, O. (Ed), Marcel Dekker.

[17] Uddin, M.S., Hawlader, M.N.A., Luo, D., and Mujumdar, A.S., Degradation of ascorbic acid in dried guava during storage. Journal of Food Engineering, $51,21-26$. 